\title{
Discussion on Application of Humanistic Thought in Piano Teaching
}

\author{
Jiangjiang Tao \\ Ningxia Normal University, Guyuan, 756000, China
}

Keywords: Humanistic thought; Piano teaching; Training; Influence

\begin{abstract}
With the social development and increase of piano audience, the piano teaching attracts more and more attention. The piano music is so fantasy that people can blend their emotion into the vast universe in the appreciation process. Human's music perception is a series of psychological activities in which the humanistic thought is integrated. This paper carries out research on the application of humanistic thought in piano teaching.
\end{abstract}

\section{Introduction}

The education purpose is not specific task or technical training, but to arouse the perception on possible prospect of human life, and trigger or cultivate people's humanistic awareness. Some people may have this awareness since their birth, and then their potential can be naturally exerted. However, as for most of people, their awareness shall be aroused. Therefore, the humanists not only pay key attention to the core position of education, but also advocate to lay a foundation of comprehensive education for the purpose of fully developing personality and exerting personal talents.

\section{Necessity of humanistic thought in piano teaching}

In the teaching, the piano music is famous for its unique charm and sense of beauty, and the flowing music contains rich tone and moving melody. The romantic, easy and light, and blustering tone and melody slightly arouse the feelings in our heart. How to penetrate into humanistic thought in the piano teaching is the deepened representation of music cultivation and aesthetic expansion.

\section{Influence of humanistic thought in piano teaching}

In the teaching of higher normal universities, there is great gap with cultivation of music talents in professional conservatory of music. In terms of objective of talent cultivation, the conservatories of music focus on professional performance and have strict requirement for music accomplishment, and seek for high-level music inspiration and performance method. However, in terms of music cultivation goal, the higher normal universities aim at cultivating music education workers for primary and secondary schools, require that the music education workers shall have good piano teaching ability and accompaniment ability, have high requirement for expression skills of music, and also require certain aesthetic ability. In terms of teaching, it is required to combine with the training objective and features of normal universities and seek for education-oriented teaching concept; the corresponding humanistic thought is just the link which connects the theory and practice of piano teaching. In the piano teaching process, the music opens the window of students' heart, and let students perceive this colorful world and happiness through music. The school days are a process of unlimited pursuit for world philosophy and confusion, and the students can obtain edification from music and finally realize the purpose of promoting students' integrated development. In the music teaching, there may exist some misunderstandings for normal universities which only regard music course as a course to teach music knowledge and cultivate music skills; however, the music shall be also explained from the cultural perspective of humanistic thought. The music is the historic product of time development and it has certain cultural value and significance; therefore, except for learning, the students shall deepen their understanding of background significance of music culture. The humanistic thought lays a good foundation for music development; if the music teaching is separated from humanistic thought, it means that the music teaching is just a subject about professional 
technology. In the piano teaching without concept of humanistic thought, the music explanation is not thorough. All the music come from development process of humanistic thought, and they are the release of human emotion; therefore, except for excellent skills, we shall also pay attention to the influence of humanistic thought on music so as to cultivate students' good music accomplishment and deep understanding of music. Under the background of music culture, it is required to cultivate and develop students' ability in exploring the music. In case of insufficient knowledge of humanistic thoughts in piano teaching, the students' musical expression ability and performance ability may be hindered. To make use of humanism spirit to cultivate students to learn piano has become an important task in piano teaching. ${ }^{[1]}$

\section{Feasibility of humanistic thought in piano teaching}

If we want to have strong analysis and understanding ability in piano teaching, we must have complete knowledge frame. For example, the professional music theory course shall be used as the compulsory course in music teaching so that the students' ability in analyzing and understanding the music. With the development of internet technology, there are very convenient means for students to obtain information, thus they can obtain very comprehensive data in art comprehension. The Standards for Art Courses issued in China clearly stipulates that the art courses shall be compulsory courses at the stage of compulsory education; while cultivating students' ability of perceiving the art, it is also required to cultivate students' comprehensive innovation ability so as to promote students' comprehensive development. The piano teaching is not a single-orientation skill, and it is required to let students carry out artistic exploration ability based on "humanity" rather than make repeated imitation and mechanical training. The feasibility of humanistic thought in piano teaching is an important means to realize integrated development of artistic ability and humanistic thought.

\section{Misunderstanding in piano teaching}

Currently, there exist some misunderstandings in the humanistic cultivation in the piano teaching; the students can't fully express humanistic feelings, and the music understanding is not realized in place.

\section{Western analysis misunderstanding}

In the piano teaching, there is a trend of loss of humanistic thought; currently, through enhancing the understanding of humanistic spirit, it is able to realize deep expansion of piano teaching. The knowledge of development history of western music and western musicians' biographies can help us to further develop humanistic feelings; however, under this condition, we can't be fully influenced by Occidentalism, but shall combine with our actual development to carry out piano teaching, and find a way suitable for development of humanistic feelings in terms of spiritual life. As for ideological trend, we shall blend in the concept core of humanism, and combine Marxism with freedom, equality, and philanthropism concepts of western humanism in the piano teaching, as well as utilize the self-improvement, self-discipline, and social commitment thought in Chinese traditional thoughts to let students get a deeper knowledge of music. ${ }^{[2]}$

\section{Technical misunderstanding in piano teaching}

The piano makes the ascent of the throne of "king of musical instrument" since the later $18^{\text {th }}$ century. With the improvement of Chinese living standard, the piano plays an important position in entertainment consumer goods in recent years, thus the playing skills of piano attract more and more attention; however, in this process, people ignore the humanity of art. The piano needs certain aesthetic feature, and the students' feeling and emotion are very important to piano performance; if we only pay attention to the training of hands and arms and pay no attention to people's thinking and psychological awareness, the piano teaching will become a behavior of putting the cart before the horse; in the piano teaching, the source which causes deeper influence is the personality and education environment. Why are there so many piano maters in the $18^{\text {th }}$ century but few art talents 
now despite of more playing skills of piano? This is the technical misunderstanding on education method. In the piano teaching, we shall carry out mutual combination of skill teaching and humanistic teaching; in this way, while the students master piano skills, they can deepen their understanding of humanistic knowledge, and pay attention to the influence of emotion on music, thus the music performance can have stronger expressive force. In the initial adjustment, the teachers can carry out slow-speed practice rather than give a wrong demonstration on style and content of music; in this way, the movement and emotion can be stabilized, which is half the battle. For example, counting the beats loudly is to motivate the emotion; if the emotion is normal, the final state is positive, gentle, and steady playing. If a person is calmer, it is easier for him or her to get resonance with the artistic conception of music. The humanistic thought causes the deepest influence on playing, and the understanding of humanistic thought can make the performance show bright color.

\section{Utilitarianism misunderstanding in piano teaching}

The utilitarianism in piano teaching includes spiritual and material aspect. In the reality, the pricing of partial piano teaching is too high to stop some children with art talents; currently, most of piano learning is regarded as a kind of means of making a living; although there is no ground for blame, as for the art, it is very adverse to learn and understand the piano; such kind of learning is full of the concept of spoiling things by excessive enthusiasm and weakens the charm of art. The art can sublimate people's emotion; for example, Beethoven's Moonlight Sonata can make people get rid of sadness and confusion and get full confidence in life; while the piano music is played, we can relax and adjust ourselves, thus it is unnecessary to add utilitarian color. The creativity and potential of piano teaching are colorful, the infection of piano music is very strong, and the solemn melody and rich tone can make people feel delightful and bright. As Einstein says, "without education of early-rising music, I will accomplish nothing”, thus we can see the importance of music teaching. The teachers are the best spreaders of piano teaching; through teachers' correct guidance, the students can correctly understand the learning of piano music. In the piano teaching, the teachers shall emphasize the humanistic thought of learning and let students exert correct subjective initiative to improve the quality of piano teaching and students' quality. ${ }^{[3]}$

\section{Application of humanistic thought in piano teaching}

\section{People orientation in piano teaching}

Currently, in China's college teaching, the form of piano teaching is very single, and only little attention is paid to students' emotional expression; therefore, the schools shall change traditional teaching mode in key teaching points and combine with the humanistic thought of music in terms of performance technology; except for seeking for skills, it is required to also pay attention to students' expression and understanding of music, the ability in understanding the music, and their music performance. In the piano teaching, we can organize students to expand the learning and practice of piano music culture to let students' learning blend in artistic conception. In the teaching, it is able to take the infusion-type teaching as orientation, and penetrate into students' exploration ability in humanistic thought to guide students to actively and positively explore the connotation of music and understand the music based on time background so that the students can further master the style of musical works. The piano teaching shall be "people oriented"; in this process, the subjects are teachers and students. The teachers play a dominant role in teaching; through the teachers' correct guidance, it is able to teach out excellent students. As for humanistic thought of piano teaching, the teachers shall be forward-looking; only humanistic-thought teaching with philosophy can better show the artistic form of piano teaching. Paying attention to technology and ignoring the art can't be the only index of piano teaching, and it is unable to break away from the humanistic connotation of piano teaching. The artistic conception and emotion of piano music must be regarded as the great pursuit and expressive mode of artistic form. 


\section{Art centering in piano teaching}

The piano music includes the composer's ideological essence; through understanding the connotation of musical works, we can establish the development veins of music and realize mutual connection in music explanation. In the teaching, we shall quote the composers' thinking on life, combine with humanistic thought and aesthetic concepts in different period, deeply know the composers' life background and style, master the overall development of piano history, and then obtain new inspiration and experience in listening to piano music and researching time literature, find out correct guidance; in this way, the piano teaching can correctly control the size, expand students' four-dimension space of piano music, and let students realize deep expression of piano culture. The traditional teaching mode can't improve students' ability in exploring humanistic thoughts, thus it is required to cultivate students' ability in comprehensive feedback on music data, and the exploration ability and artistic inspiration ability of piano music are especially important. The piano not only requires people's performance ability and creation ability, but also can represent people's rich inner world; only rich spiritual activities can arouse the listeners' resonance, and the piano performance is also a kind of special ideology of human society. ${ }^{[4]}$

\section{Reference to development course in piano teaching}

The piano teaching has a long history, and the development and prosperity of piano teaching require continuous exploration and research; in the development field of art, the function of humanistic view can’t be ignored, and the construction of humanistic thought lays a good development function in future piano teaching. We can make full use of and know the development history of piano art; for example, in the Baroque, Vienna, Romanism, impressionism, and modern music period, they have respective piano culture features; the musical creation in each period is the product of historical development, and it seems that they are independent but linked with each other; only after we get a clear knowledge of history of music development, we can express the works in the performance. The musician Schuman has said: "we shall learn the history of music, listen to classical works in each time, and enrich our knowledge in this aspect so that we can remove our shortcoming of vanity and over-confidence well. Through accurately listening to classical works, it is able to avoid unnecessary music mistakes, and the rational knowledge on predecessors not only can promote our aesthetic appreciation, but also can make the vision of piano learning wider. ${ }^{[5]}$

\section{Conclusion}

Through adding the concept of humanistic thought in piano teaching, it is able to promote students to improve their music accomplishment and then influence the quality of piano teaching, which is of accurate guidance significance for students to master piano music. The teaching and development of piano music can't be separated from people's perception on music; in order to get a deeper understanding of the style of piano music, we shall make use of humanistic thought to exert its function.

\section{References}

[1] Lu Ming. Humanistic View on Keys - Another Thinking of Piano Teaching, Jiaoxiang Journal of Xi'an Conservatory of Music, 2013,32(1):140-142.DOI:10.

[2] Yuan Qin, Yuan Jin. Cultivation of Students' Musical Humanistic Exploration Ability in Piano Teaching, Vocational \& Technical Education Forum, 2011, (35): 84-85.

[3] Tang Ling. Discussion on Current Situation of Cultivation of Students' Musical Humanistic Exploration Ability in Piano Teaching and Measures, Journal of Mudanjiang College of Education, 2014,(9):108-109.DOI:10. 
[4] Jiang Xiaoyan. Cultivation of Humanistic Accomplishment and Vocational Ability in Piano Teaching of Normal Universities, Art Criticism, 2011, (5): 109-113. DOI: 10.

[5] Zou Li. Discussion on Shaping and Influence of Humanistic Knowledge on Students' Psychological Experience in Piano Teaching, Shaanxi Education (Higher Education), 2011,(8):138-139. 